\title{
Upregulation of long non-coding RNA PRNCR1 in colorectal cancer promotes cell proliferation and cell cycle progression
}

\author{
LIU YANG $^{1,2^{*}}$, MANTANG QIU ${ }^{2,3^{*}}$, YOUTAO XU ${ }^{3 *}$, JIE WANG $^{4}$, \\ YANYAN ZHENG ${ }^{5}, \mathrm{MING} \mathrm{LI}^{3}, \mathrm{LIN} \mathrm{XU}^{3}$ and RONG YIN ${ }^{3}$

\begin{abstract}
${ }^{1}$ Colorectal Cancer Center, Nanjing Medical University Affiliated Cancer Hospital, Jiangsu Key Laboratory of Molecular and Translational Cancer Research, Cancer Institute of Jiangsu, Nanjing, Jiangsu $210009{ }^{2}{ }^{2}$ The Fourth Clinical College of
\end{abstract} \\ Nanjing Medical University, Nanjing, Jiangsu 210000; Departments of ${ }^{3}$ Thoracic Surgery, ${ }^{4}$ Scientific Research and ${ }^{5}$ Nursing, \\ Nanjing Medical University, The Affiliated Cancer Hospital, Cancer Institute of Jiangsu, Nanjing, Jiangsu 210009, P.R. China
}

Received June 23, 2015; Accepted August 11, 2015

DOI: $10.3892 /$ or.2015.4364

\begin{abstract}
Colorectal cancer (CRC) is one of the most common cancers worldwide. Long non-coding RNAs (lncRNAs) have been confirmed to play a critical regulatory role in various biological processes including carcinogenesis, which indicates that lncRNAs are valuable biomarkers and therapeutic targets. The novel lncRNA prostate cancer non-coding RNA 1 (PRNCR1) is located in the susceptible genomic area of CRC, however the functional role of PRNCR1 remains unknown. Thus, we aimed to investigate the clinical significance and biological function of PRNCR1 in CRC. Quantitative real-time polymerase chain reaction (qRT-PCR) was used to assess the expression profile of PRNCR1 in CRC tissues and cell lines. An antisense oligonucleotide (ASO) was designed to knock down PRNCR1. In a cohort of 63 patients, PRNCR1 was significantly overexpressed in CRC tissues compared with the expression in adjacent tissues, with an average fold increase of $10.55(\mathrm{P}=0.006)$. Additionally, a high level of PRNCR1 was associated with large tumor volume $(\mathrm{P}<0.05)$. Based on receiver operating characteristic curve (ROC), we found that the area under the curve (AUC) of PRNCR1 was 0.799 while the AUC of conventional biomarker CEA-CA199 was 0.651, indicating that PRNCR1 could be a sensitive diagnostic biomarker of CRC. Compared with the
\end{abstract}

Correspondence to: Dr Lin Xu or Dr Rong Yin, Department of Thoracic Surgery, Nanjing Medical University, The Affiliated Cancer Hospital, Cancer Institute of Jiangsu, 42 Baiziting, Nanjing, Jiangsu 210009, P.R. China

E-mail: xulin83cn@gmail.com

E-mail: yinhero001@126.com

*Contributed equally

Key words: PRNCR1, long non-coding RNA, colorectal cancer, proliferation normal human colorectal epithelial cell line (FHC), PRNCR1 was upregulated in most CRC cell lines (HCT116, SW480, LoVo and HT-29). After knockdown of PRNCR1 by ASO, CRC cell proliferation ability was significantly inhibited. We further found that PRNCR1 knockdown induced cell cycle arrest in the G0/G1 phase and a significant decrease in the proportion of cells in the $\mathrm{S}$ phases. In contrast, PRNCR1 knockdown did not affect cell apoptosis or invasive ability. Hence, these data indicate that PRNCR1 promotes the proliferation of CRC cells and is a potential oncogene of CRC.

\section{Introduction}

Colorectal cancer (CRC) is the third most common cancer in males, the second in females and the fourth leading cause of cancer-related death worldwide. In 2008, more than 1.2 million new CRC cases and 608,700 deaths were caused by CRC; notably, the highest incidence rates are found in The Occident, especially in males (1). However, CRC incidence rates are rapidly increasing in the Asian countries (2).

Among all the risk factors that may cause CRC directly, molecular and genic effects are the dominant causes. Since there are multiple unknown carcinogens and varying genetic backgrounds, it is difficult to determine which factor is the most important during the development of CRC (3). Moreover, lack of efficient early diagnostic biomarkers, such as an actual molecule involved in the progression of CRC, urges pathbreaking studies on these aspects.

Increasing evidence shows that non-coding genes may be strictly accountable for the gene expression complexity in humans (4-6). Non-coding RNAs (ncRNAs) are proven to be the key regulators in the process of transcription and expression, which could be divided into small ncRNAs $(<200 \mathrm{nt})$ and long ncRNAs (lncRNAs) (7,8). An increasing number of studies have focused on the functional hot spot of lncRNAs in their roles as regulators of biological processes, such as genomic imprinting, chromatin modification and post-transcriptional processing (9-11), displaying more complex regulatory mechanisms than microRNAs $(12,13)$. In cis- and trans-regulatory mechanisms $(14,15)$, IncRNAs have been 
shown to play important roles in various human diseases, especially in malignant tumors (16-19).

Prostate cancer non-coding RNA 1 (PRNCR1), also known as PCAT8 and CARLo-3, is a $\sim 13 \mathrm{~kb}$ intron-less lncRNA, which is transcribed from the 'gene-desert' region of 8q24 (20). It has been reported that PRNCR1 is associated with prostate cancer susceptibility and PRNCR1 could be involved in prostate carcinogenesis by modulating androgen receptor (AR) activity. This mechanism was further described by Yang et al. Binding of PRNCR1 to the acetylated AR and its association with DOT1L appear to be required for recruitment of a second lncRNA, PCGEM1, to the DOT1L-mediated methylated of AR at the N-terminus. The interactions of these overexpressed lncRNAs may potentially serve as important regulators in prostate cancer (21). For CRC, many researchers have reported that the crucial locus of $8 \mathrm{q} 24$ may contribute to susceptibility to CRC $(22,23)$. It has been gradually recognized that aberration of PRNCR1 might be a biological signature of CRC, but its specific expression pattern related to CRC remains unknown.

In this study, we identified the PRNCR1 expression profile in CRC patients and assessed the association between PRNCR1 expression and clinicopathological features. By using antisense oligonucleotide (ASO)-mediated inhibition, we evaluated the impact of PRNCR1 on cancer cell proliferation, apoptosis, migration and invasion in vitro.

\section{Materials and methods}

Patients and tissue samples. This study was approved by the Ethics Committee of the Cancer Institute of Jiangsu, and written informed consent was obtained from all patients. A total of 63 pairs of primary CRC tissues and adjacent normal tissues ( $5 \mathrm{~cm}$ or more from tumor tissues) were collected from patients who had undergone surgery at the Colorectal Cancer Center, Cancer Institute of Jiangsu, between 2013 and 2014. Patients who received chemotherapy or radiotherapy before surgery were excluded. All tumor specimens were collected immediately after removal from the resected colorectum, frozen and stored at $-80^{\circ} \mathrm{C}$. All tumors and paired normal tissues were ascertained by experienced pathologists. The clinical and pathological characteristics for each patient were also collected.

RNA extraction and $q R T-P C R$ analyses. Total RNA was extracted from tissues or cultured cells with TRIzol reagent (Life Technologies, Gaithersburg, Scotland, UK) according to the manufacturer's protocol. Total RNA $(1.5 \mu \mathrm{g})$ was reverse transcribed in a final volume of $20 \mu \mathrm{l}$ using random primers under standard conditions using the PrimeScript $\mathrm{R}^{\mathrm{TM}}$ Master Mix (cat. no. RR036A; Takara Bio, Inc., Dalian, China).

After the RT reaction, qRT-PCR was performed using the SYBR Select Master Mix (cat. no. 4472908; Applied Biosystems, Foster City, CA, USA) with $0.5 \mu$ l complementary DNA (cDNA) on an ABI 7300 system (Applied Biosystems) according to the manufacturer's instructions. By using $\beta$-actin as an internal control, the PRNCR1 expression level was determined by qRT-PCR using the following primer sequences: forward, 5'-CCAGATTCCAAGGGCTGATA-3' and reverse, 5'-GATGTTTGGAGGCATCTGGT-3'. The forward primer sequences for the $\beta$-actin primer were 5'-CCAGATTCCAAG GGCTGATA-3' and reverse for $\beta$-actin were 5'-GATGTT TGGAGGCATCTGGT-3'. The qRT-PCR reaction included an initial denaturation step at $95^{\circ} \mathrm{C}$ for $10 \mathrm{~min}$, followed by 40 cycles of $92^{\circ} \mathrm{C}$ for $15 \mathrm{sec}$ and $60^{\circ} \mathrm{C}$ for $1 \mathrm{~min}$. The $\mathrm{Ct}$ value for each sample was calculated with the $\Delta \Delta \mathrm{Ct}$ method, and fold-changes in expression (tumor vs. normal) were calculated using $2^{-\Delta \Delta \mathrm{Ct}}$ methods (24).

Cell culture and ASO transfection. Three CRC cell lines, SW620,HCT116 and SW480, were obtained from the Shanghai Institutes for Biological Science, Shanghai, China. LoVo and HT-29 cells were donated by Dr Zhicheng Chen (Department of Anorectal Clinic, The Medical School of Southeast University). A normal human colorectal epithelial cell line (FHC) was purchased from ScienCell Research Laboratories.

All cell lines were grown in RPMI-1640 medium (Kaiji, Nanjing, China) at $37^{\circ} \mathrm{C}$ in a humidified $5 \% \mathrm{CO}_{2}$ atmosphere. The CRC cell lines at $50 \%$ confluency were transfected with $100 \mathrm{nM}$ of either the ASO targeting PRNCR1 or scrambled negative controls (GenePharma, Shanghai, China) using Lipofectamine RNAimax reagent (Invitrogen Inc., Carlsbad, CA, USA) according to the instructions provided by the manufacturer. The ASO sequences were as follows: ASO-1 for PRNCR1, 5'-ACUCUCCTTCTCCACCUCCA-3'; ASO-2 for PRNCR1, 5'-ACUCCCACACCACCACCACC-3' and scrambled ASO, 5'-AAGCGCGCACCAGCGCCUCC-3', which were designed by a professional website (http://www. idtdna.com/Scitools/Applications/AntiSense/Antisense.aspx? source $=$ menu).

Cell proliferation assay. Cell proliferation was assayed by the Cell Counting Kit-8 (CCK-8) assay (Promega, Madison, WI, USA) according to the manufacturer's protocol. The transfected cells were plated in 96-well plates (2,000 cells/well). Following the manufacturer's protocol, cell proliferation was detected every $24 \mathrm{~h}$. In brief, $10 \mu \mathrm{l}$ of CCK- 8 solution was added to each well and incubation was carried out for $2 \mathrm{~h}$ at $37^{\circ} \mathrm{C}$. Then, each solution was measured spectrophotometrically at $450 \mathrm{~nm}$.

In vitro cell migration and invasion assays. HT-29 cells transfected with $100 \mathrm{nM}$ ASO-PRNCR1 or scramble were harvested after $24 \mathrm{~h}$. For the migration assays, the transfected cells $\left(2.5 \times 10^{5}\right)$ were plated in the upper chamber of Transwell assay inserts (Millipore, Billerica, MA, USA) containing $200 \mu \mathrm{l}$ of serum-free DMEM with a membrane (8-mm pores). Then the inserts were placed into the wells of the bottom chamber of a 24-well plate filled with conditioned medium. After $24 \mathrm{~h}$ of incubation, the cells on the filter surface were fixed with methanol, stained with crystal violet, and photographed with a digital microscope. Cell numbers were calculated in five random fields for each chamber.

For the invasion assays, the transfected cells $\left(4 \times 10^{5}\right)$ were plated in the top chamber with a Matrigel-coated membrane (BD Biosciences) in $500 \mu 1$ serum-free RPMI-1640 accompanied by $750 \mu 1$ 10\% FBS-RPMI-1640 in the bottom chamber. After a 48-h incubation period, the invasive ability was assessed as mentioned previously for the migration assay. 
Table I. Correlation between PRNCR1 expression and clinicopathological characteristics of the CRC patients.

\begin{tabular}{|c|c|c|c|}
\hline Characteristics & No. $(\%)$ & Fold-change & P-value \\
\hline Total & $63(100)$ & & \\
\hline Age (years) & & & $0.596^{\mathrm{a}}$ \\
\hline$\geq 60.22^{\mathrm{d}}$ & $34(53.97)$ & 10.73 & \\
\hline$<60.22^{\mathrm{d}}$ & $29(46.03)$ & 15.69 & \\
\hline Gender & & & $0.888^{\mathrm{b}}$ \\
\hline Male & $37(58.73)$ & 15.30 & \\
\hline Female & $26(41.27)$ & 9.76 & \\
\hline Family history & & & $0.253^{\mathrm{b}}$ \\
\hline Positive & 17 (26.98) & 6.56 & \\
\hline Negative & $46(73.02)$ & 15.40 & \\
\hline Tumor site & & & $0.632^{\mathrm{b}}$ \\
\hline Below decending colon & $49(77.78)$ & 14.85 & \\
\hline Above sigmoid colon & $14(22.22)$ & 6.59 & \\
\hline Tumor size $\left(\mathrm{cm}^{3}\right)$ & & & $0.012^{\mathrm{a}}$ \\
\hline$\geq 23.53^{\mathrm{e}}$ & $18(28.57)$ & 19.17 & $0.018^{\mathrm{f}}$ \\
\hline$<23.53^{\mathrm{e}}$ & $45(71.43)$ & 10.55 & \\
\hline Differentiation & & & $0.491^{\mathrm{b}}$ \\
\hline Poor & $25(39.68)$ & 13.87 & \\
\hline Moderate or high & $38(60.32)$ & 12.45 & \\
\hline T stage & & & $0.087^{\mathrm{b}}$ \\
\hline Entire serosal invasion & $52(82.54)$ & 12.60 & \\
\hline Subserous invasion & $11(17.46)$ & 14.94 & \\
\hline $\mathrm{N}$ stage & & & $0.775^{\mathrm{b}}$ \\
\hline Positive & $28(44.44)$ & 18.81 & \\
\hline Negative & $35(55.56)$ & 15.05 & \\
\hline M stage & & & $0.756^{\mathrm{b}}$ \\
\hline Positive & $11(17.46)$ & 13.32 & \\
\hline Negative & $52(82.54)$ & 12.95 & \\
\hline
\end{tabular}

${ }^{\text {aP}} \mathrm{P}$-value of Mann-Whitney test. ${ }^{\mathrm{b}} \mathrm{P}$-value of Spearman's test. 'Significant correlation after univariate analysis. ${ }^{\mathrm{d}}$ Mean age of the patients. ${ }^{\mathrm{e}}$ Mean volume of the tumors. ${ }^{\mathrm{f}}$ Significant correlation after multivariate analysis.

Flow cytometric analysis. Transfected cells were harvested after transfection. HT-29 cells were stained with Annexin V and propidium iodide (PI) using Annexin V-FITC/PI apoptosis detection kits (BD Biosciences) and then examined by flow cytometry (FACScan; BD Biosciences). Cells were discriminated into viable cells, early apoptotic cells, apoptotic cells and dead cells. Cells for cell cycle analysis were stained with PI by the Cycletest ${ }^{\mathrm{TM}}$ Plus DNA Reagent kit (BD Biosciences) and analyzed by FACScan.

Statistical analysis. The Student's t-test, Spearman's test, and one-way AVONA, the receiver operating characteristic (ROC) curve, binary correlation analysis and logistic regression were performed to analyze the data. The ROC curve was calculated to estimate the diagnostic efficiency of PNRCR1, and the cut-off value of best diagnostic efficiency was also determined. All statistical analyses were performed with SPSS software package (version 19.0; SPSS Inc.). All P-values were two-sided, and $\mathrm{P}<0.05$ was considered to indicate a statistically significant difference.

\section{Results}

Correlation between PRNCRI expression and clinical characteristics. The PRNCR1 expression levels were analyzed in 63 paired primary CRC and adjacent non-cancerous tissues. It was found that PRNCR1 was significantly overexpressed in CRC, with an average fold increase of $10.55(\mathrm{P}=0.006)$ (Fig. 1A). Then, the association between PRNCR1 expression and clinicopathological parameters was explored. As shown in Table I, tumor volume was significantly associated with the expression level of PRNCR1 after univariate and multivariate analyses. Specifically, the PRNCR1 expression level was higher in patients with a large volume tumor [Fig. 1B and Table I; large vs. small, 19.17 vs. $10.55 ; \mathrm{P}_{\text {univariate }}=0.012, \mathrm{P}_{\text {multivariate }}=0.018$ $(\mathrm{OR}=5.227$; CI, 1.328-20.581)]. PRNCR1 expression was not correlated with gender, age, tumor site, differentiation, family history or TNM stage.

Expression profile of PRNCRI in CRC cell lines. Initially, the expression profile in CRC cell lines was first assessed by qRT-PCR. When normalized to the FHC cells, the expression level of PRNCR1 was upregulated in most CRC cell lines (Fig. 2A). Specifically, PRNCR1 was upregulated in the HCT116, SW480, LoVo and HT-29 cells but was downregulated in the SW620 cells.

PRNCR1 promotes the proliferation of CRC cell lines in vitro. Primarily, two ASOs specifically targeting PRNCR1 were designed to knock down PRNCR1 in vitro. Based on the relatively higher expression of PRNCR1, HT-29 cells were transfected with ASO-PRNCR1 or scramble. At $36 \mathrm{~h}$ after treatment, PRNCR1 expression was effectively knocked down (Fig. 2B). CCK8 assay showed that knockdown of PRNCR1 significantly inhibited cell proliferation in the HT-29 cell line (Fig. 2C). Then, we evaluated whether PRNCR1 could impact proliferation of CRC cells by altering the rate of apoptosis or cell cycle progression. Flow cytometric analysis was performed, and the results revealed that ASO treatment blocked HT-29 cells at the G0/G1 phase with a concomitant decrease of cells in the $\mathrm{S}$ phase (Fig. 3A). However, inhibition of PRNCR1 by ASO did not affect apoptosis (Fig. 3B).

Furthermore, Transwell invasion and Matrigel invasion assays revealed that ASO-PRNCR1 treatment did not affect the migration and invasion capacities compared to the scramble control (Fig. 4). These results suggest that PRNCR1 promotes the proliferation of CRC cells.

Diagnostic value of PRNCR1. To further evaluate the potential diagnostic value of PRNCR1, an ROC curve was generated to assess the potential of PRNCR1 as an early diagnostic biomarker for CRC. As shown in Fig. 5, the area under the curve (AUC) was 0.799>0.5, which was higher than CEA-CA199 (AUC=0.651), indicating that PRNCR1 might have adequate potential as a biomarker. According to 
A

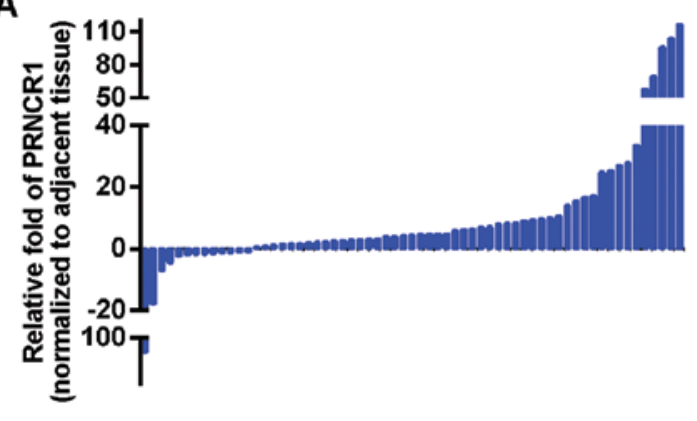

B

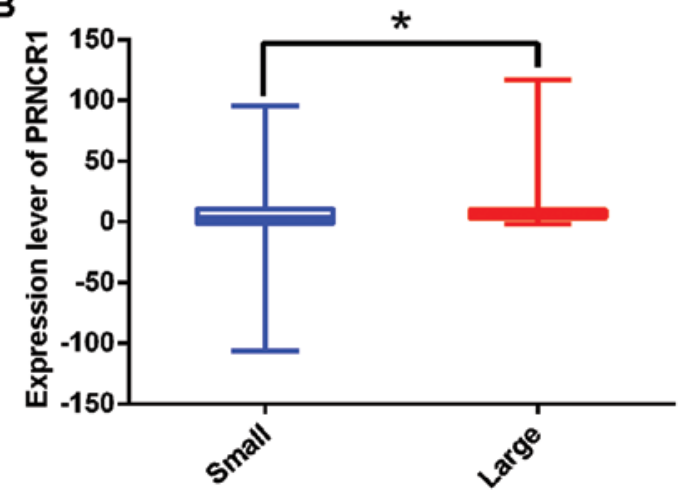

Figure 1. Analysis of PRNCR1 expression in the CRC tissues. (A) PRNCR1 was detected in 63 pairs of CRC tissues by qRT-PCR. The level of PRNCR1 in the $\mathrm{CRC}$ tissues was significantly higher than the level in the non-tumorous tissues $(\mathrm{P}=0.006)$. (B) PRNCR1 was upregulated in a group of tumors with a large volume $(\mathrm{P}=0.012)(\mathrm{P}<0.05)$.

A

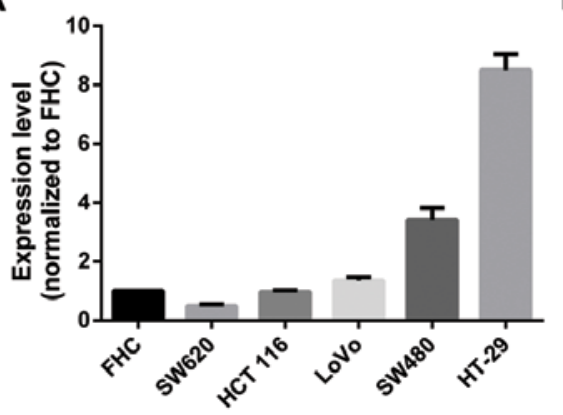

B

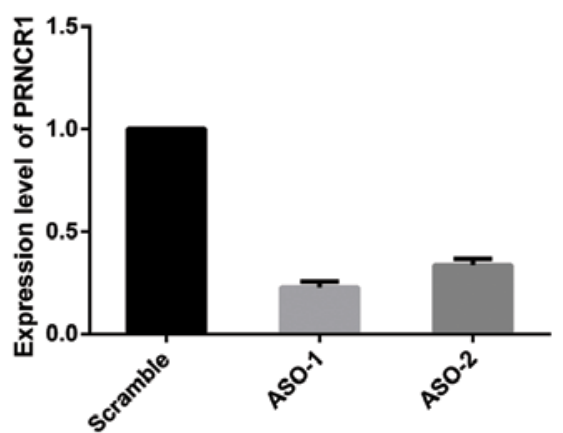

C

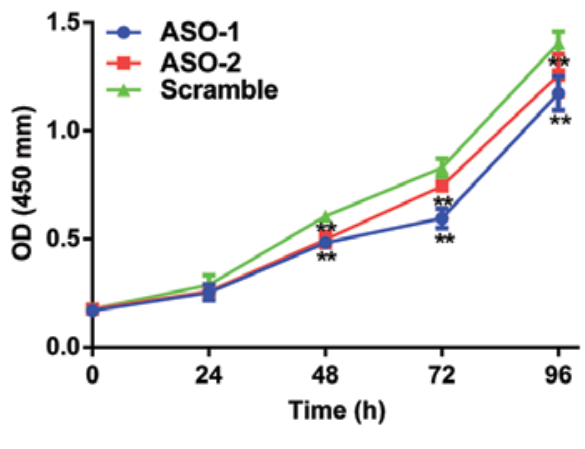

Figure 2. Analysis of the PRNCR1 expression in CRC cells and the silencing efficiency of ASO transfection. (A) Among the CRC cells, when compared to FHC cells, PRNCR1 was upregulated in the LoVo, SW480 and HT-29 cells but downregulated in the SW620 and HCT 116 cells. The HT-29 cell line showed the highest expression level ( $\sim 8.4$ fold). (B) PRNCR1 expression in the HT-29 cells after transfection of scramble or ASO. ASO-2 showed better inhibition efficiency. (C) Cell proliferation assay by CCK-8 assay. ASO-mediated silencing of PRNCR1 significantly inhibited cell proliferation in the HT-29 cells ( ${ }^{* *}$ P $\left.<0.01\right)$.

A
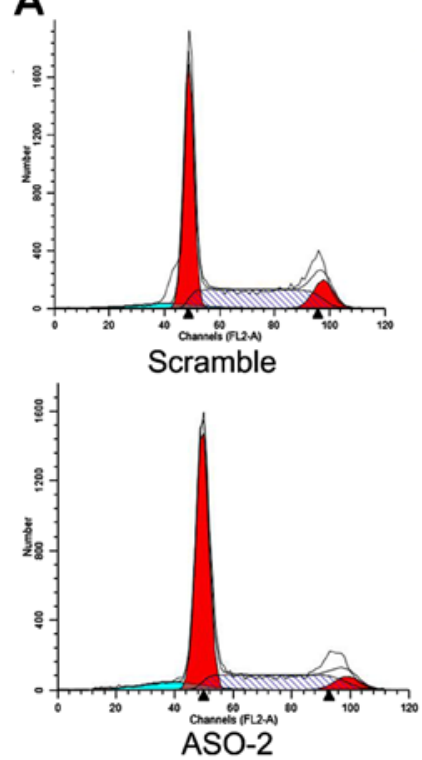
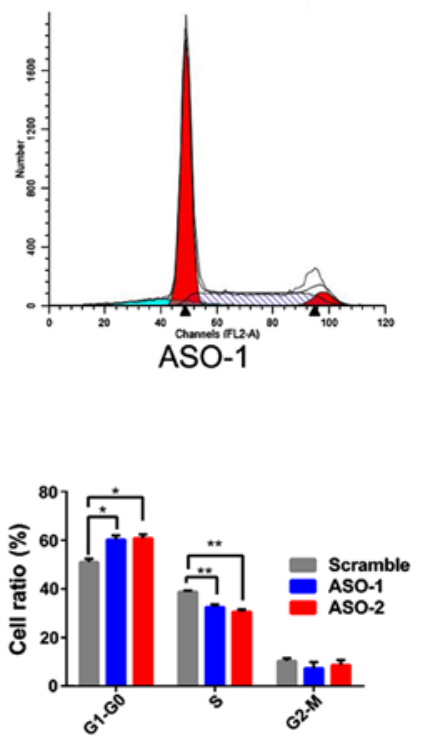

B
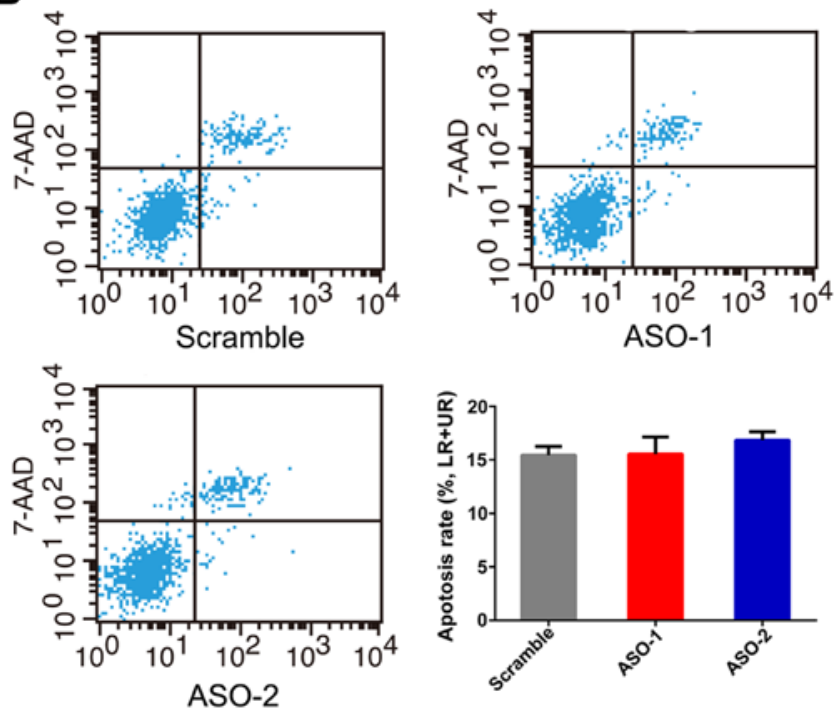

Figure 3. Impacts of PRNCR1 on the cell cycle and apoptosis of HT-29 cells as analyzed by flow cytometry. (A) After transfection, HT-29 cells were prevented from G1 to S phase progression. ASO treatment blocked HT-29 cells at the G1 phase and inhibited DNA synthesis significantly. (B) Silencing of PRNCR1 did not affect apoptosis $\left({ }^{*} \mathrm{P}<0.05 ;{ }^{* *} \mathrm{P}<0.01\right)$. 
A

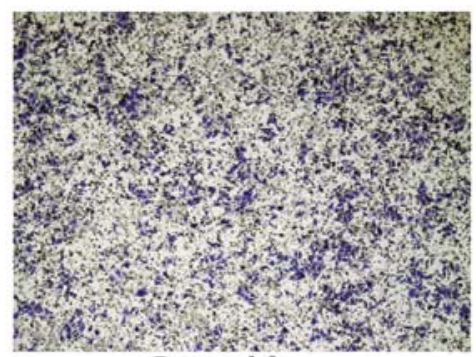

Scramble

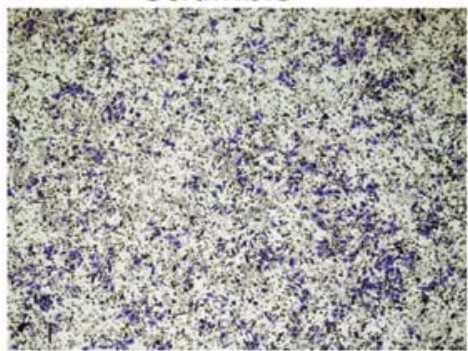

ASO-2

B

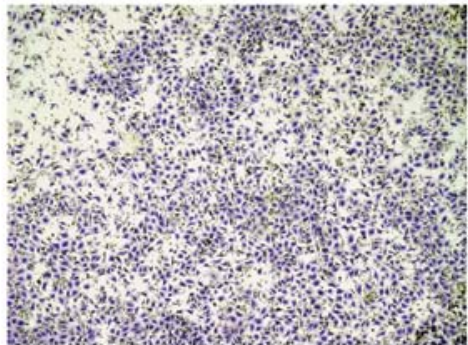

Scramble

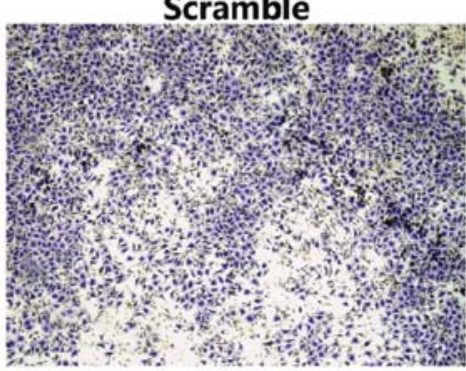

ASO-2

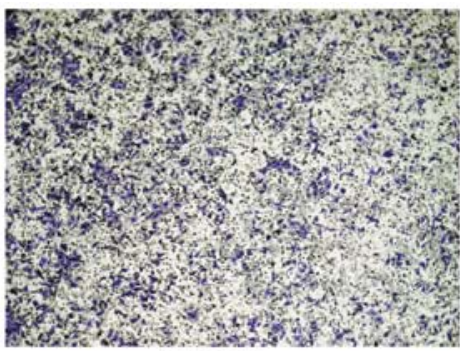

ASO-1
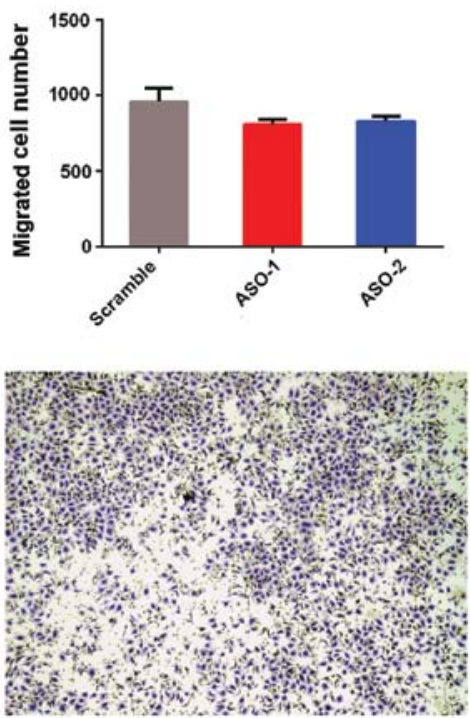

ASO-1

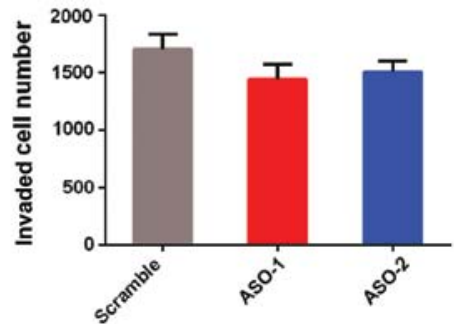

Figure 4. After transfection, the migration (A) and invasion (B) capabilities did not show significant changes in the HT-29 cells.

-the evaluation of the ROC curve, a cut-off value of 2.934 of a fold-change of PRNCR1 maximized the sensitivity $(84.8 \%)$ and specificity $(70.0 \%)$ in predicting the risk of $\mathrm{CRC}$, and showed better efficiency than CEA-CA199.

\section{Discussion}

lncRNAs are involved in every aspect of cancer progression, such as initiation, cancer metastasis, and could function as oncogenes and tumor suppressors (22). PRNCR1 can promote the progression of prostate cancer, yet the function and molecular mechanism in CRC remain unknown $(20,21,25,26)$.

In the present study, we assessed the relationship between PRNCR1 expression and clinical characteristics of CRC patients and the possible function of PRNCR1 was probed by ASO-mediated inhibition in CRC cells. PRNCR1 expression was found to be increased in CRC tissues compared to the level in paired adjacent normal tissues. ASO-mediated silencing of PRNCR1 in HT-29 cells showed that silencing of PRNCR1

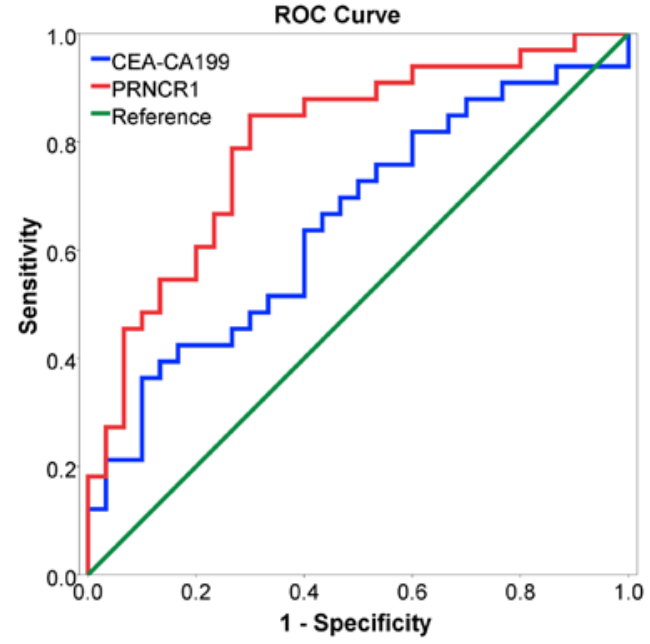

Figure 5. ROC curves for PRNCR1 and CEA-CA199. A cut-off value of a fold-change of 2.934 of PRNCR1 maximized the sensitivity (84.8\%) and specificity $(70.0 \%)$ in predicting the risk of CRC. PRNCR1 showed better efficiency than CEA-CA199. 
inhibited the proliferation and blocked cell cycle progression in the HT-29 cells. These data suggest that PRNCR1 may play an important role in CRC.

In addition, our results also indicated that a high level of PRNCR1 expression was markedly correlated with large tumor volume. In addition, it has been found that patients carrying the rs1456315G polymorphism have a tumor of much larger size (22). This could be explained by the following reasons. Primarily, the predicted secondary structure of PRNCR1 mRNA might be influenced by SNPs in PRNCR1, shifting the stability of the lncRNA PRNCR1 (20). Secondly, in terms of our findings, the silencing of PRNCR1 blocked the cell cycle at the G0/G1 phase indicating that PRNCR1 promotes the proliferation of CRC cells, and eventually may bring about larger tumor volume eventually.

Based on a literature review, five SNPs, rs13252298, rs1456315, rs1456315G, rs7007694C and rs16901946G, located in the IncRNA PRNCR1 exhibit a strong relationship with CRC tumorigenesis and development (22). Moreover, emerging genome-wide association studies (GWAS) show that a CpG site at Chr8: 128167809 in PRNCR1 and CRC susceptibility SNP rs1456315G have been found to be highly correlated with each other (27-29). In addition, correlations of these DNA methylation levels at $\mathrm{CpG}$ sites with each other within or nearby the GG genotype of rs6983267 in colon cancer associated transcript 2 (CCAT2) could be linked with c-MYC by enhancing Wnt signaling to upregulate transcription of CCAT2 (30-33), suggesting the homologous impact on PRNCR1. In agreement with our hypothesis, a previous study identified correlations for DNA methylation levels at CpG sites located near one another, especially those within distances equivalent to 1-2 kb apart (34). Moreover, compared with the functional mechanism of PRNCR1 in prostate cancer cells $(20,21)$, a similarity may exist in CRC; however, much more research is still required to scrutinize all feasible targets of the characteristic site.

Disappointedly, no correlation between PRNCR1 and invasion, migration, apoptosis, differentiation and TNM stages of CRC was noted. The likely cause of this could be explained as follows. Poor differentiation of CRC cells furthers high metastatic and malignant potentials (35). Patients with SNPs in PRNCR1 have decreased risks to develop poorly differentiated CRC, while others with SNPs in PRNCR1 have increased risks (22). This may be why increased PRNCR1 expression may not relate to worse clinical characteristic of CRC.

Likewise, we detected the diagnostic value of PRNCR1 by ROC analysis, and PRNCR1 showed better predictive efficiency than serum biomarker CEA-CA199, indicating that PRNCR1 may be a potential biomarker for CRC diagnosis.

To sum up, we found that PRNCR1 is upregulated in CRC tissues and the upregulation of PRNCR1 is associated with large tumor volume. In addition, knockdown of PRNCR1 significantly inhibited proliferation and induced cell cycle arrest at the G0/G1 phase in the CRC cells, Moreover, PRNCR1 potentially could be an efficient predictive biomarker.

\section{Acknowledgements}

We thank Dr Zhicheng Chen (Department of Anorectal Clinic, Medical School of Southeast University) for gifting the CRC cells. This study was funded by the Natural Science Foundation of China (81372321 to L.X.; 81201830 and 81472200 to R.Y.), the Natural Science Foundation for High Education of Jiangsu Province (13KJB320010 to R.Y.), and Jiangsu Provincial Special Program of Medical Science (BL2012030 to L.X.).

\section{References}

1. Jemal A, Bray F, Center MM, Ferlay J, Ward E and Forman D: Global cancer statistics. CA Cancer J Clin 61: 69-90, 2011.

2. Center MM, Jemal A and Ward E: International trends in colorectal cancer incidence rates. Cancer Epidemiol Biomarkers Prev 18: 1688-1694, 2009.

3. Han Y, Yang YN, Yuan HH, Zhang TT, Sui H, Wei XL, Liu L, Huang P, Zhang WJ and Bai YX: UCA1, a long non-coding RNA up-regulated in colorectal cancer influences cell proliferation, apoptosis and cell cycle distribution. Pathology 46: 396-401, 2014.

4. Kapranov P, Willingham AT and Gingeras TR: Genome-wide transcription and the implications for genomic organization. Nat Rev Genet 8: 413-423, 2007.

5. Kapranov P, Cheng J, Dike S, Nix DA, Duttagupta R, Willingham AT, Stadler PF, Hertel J, Hackermüller J, Hofacker IL, et al: RNA maps reveal new RNA classes and a possible function for pervasive transcription. Science 316 : 1484-1488, 2007.

6. Esteller M: Non-coding RNAs in human disease. Nat Rev Genet 12: 861-874, 2011.

7. Bartel DP: MicroRNAs: Target recognition and regulatory functions. Cell 136: 215-233, 2009.

8. Mattick JS: RNA regulation: A new genetics? Nat Rev Genet 5: 316-323, 2004.

9. Lee JT and Bartolomei MS: X-inactivation, imprinting and long noncoding RNAs in health and disease. Cell 152: 1308-1323, 2013.

10. Yoon JH, Abdelmohsen K and Gorospe M: Posttranscriptional gene regulation by long noncoding RNA. J Mol Biol 425: 3723-3730, 2013.

11. Marchese FP and Huarte M: Long non-coding RNAs and chromatin modifiers: Their place in the epigenetic code. Epigenetics 9: 21-26, 2014.

12. Wilusz JE, Sunwoo H and Spector DL: Long noncoding RNAs: Functional surprises from the RNA world. Genes Dev 23: 1494-1504, 2009.

13. Wapinski O and Chang HY: Long noncoding RNAs and human disease. Trends Cell Biol 21: 354-361, 2011.

14. Huarte M, Guttman M, Feldser D, Garber M, Koziol MJ, Kenzelmann-Broz D, Khalil AM, Zuk O, Amit I, Rabani M, et al: A large intergenic noncoding RNA induced by p53 mediates global gene repression in the p53 response. Cell 142: 409-419, 2010.

15. Nagano $T$ and Fraser P: No-nonsense functions for long noncoding RNAs. Cell 145: 178-181, 2011.

16. Li J, Xuan Z and Liu C: Long non-coding RNAs and complex human diseases. Int J Mol Sci 14: 18790-18808, 2013.

17. Deng K, Guo X, Wang H and Xia J: The IncRNA-MYC regulatory network in cancer. Tumour Biol 35: 9497-9503, 2014.

18. He X, Tan X, Wang X, Jin H, Liu L, Ma L, Yu H and Fan Z: C-Myc-activated long noncoding RNA CCAT1 promotes colon cancer cell proliferation and invasion. Tumour Biol 35: 12181-12188, 2014.

19. Xue Y, Ma G, Gu D, Zhu L, Hua Q, Du M, Chu H, Tong N, Chen J, Zhang Z, et al: Genome-wide analysis of long noncoding RNA signature in human colorectal cancer. Gene 556: 227-234, 2015.

20. Chung S, Nakagawa H,Uemura M,Piao L, Ashikawa K, Hosono N, Takata R, Akamatsu S, Kawaguchi T, Morizono T, et al: Association of a novel long non-coding RNA in 8q24 with prostate cancer susceptibility. Cancer Sci 102: 245-252, 2011.

21. Yang L, Lin C, Jin C, Yang JC, Tanasa B, Li W, Merkurjev D, Ohgi KA, Meng D, Zhang J, et al: IncRNA-dependent mechanisms of androgen-receptor-regulated gene activation programs. Nature 500: 598-602, 2013.

22. Li L, Sun R, Liang Y, Pan X, Li Z, Bai P, Zeng X, Zhang D, Zhang L and Gao L: Association between polymorphisms in long non-coding RNA PRNCR1 in 8q24 and risk of colorectal cancer. J Exp Clin Cancer Res 32: 104, 2013. 
23. Barry KH, Moore LE, Sampson J, Yan L, Meyer A, Oler AJ, Chung CC, Wang Z, Yeager M, Amundadottir L, et al: DNA methylation levels at chromosome 8q24 in peripheral blood are associated with 8q24 cancer susceptibility loci. Cancer Prev Res (Phila) 7: 1282-1292, 2014.

24. VanGuilder HD, Vrana KE and Freeman WM: Twenty-five years of quantitative PCR for gene expression analysis. Biotechniques 44 (Suppl 5): 619-626, 2008

25. Pestell RG and Yu Z: Long and noncoding RNAs (lnc-RNAs) determine androgen receptor dependent gene expression in prostate cancer growth in vivo. Asian J Androl 16: 268-269, 2014.

26. Pomerantz MM, Beckwith CA, Regan MM, Wyman SK, Petrovics G, Chen Y, Hawksworth DJ, Schumacher FR, Mucci L, Penney KL, et al: Evaluation of the 8q24 prostate cancer risk locus and MYC expression. Cancer Res 69: 5568-5574, 2009.

27. Haiman CA, Patterson N, Freedman ML, Myers SR, Pike MC, Waliszewska A, Neubauer J, Tandon A, Schirmer C, McDonald GJ, et al: Multiple regions within 8q24 independently affect risk for prostate cancer. Nat Genet 39: 638-644, 2007.

28. Xu J, Mo Z, Ye D, Wang M, Liu F, Jin G, Xu C, Wang X, Shao Q, Chen Z, et al: Genome-wide association study in Chinese men identifies two new prostate cancer risk loci at $9 \mathrm{q} 31.2$ and 19q13.4. Nat Genet 44: 1231-1235, 2012.

29. Bensen JT, Xu Z, Smith GJ, Mohler JL, Fontham ET and Taylor JA: Genetic polymorphism and prostate cancer aggressiveness: A case-only study of 1,536 GWAS and candidate SNPs in African-Americans and European-Americans. Prostate 73: $11-22,2013$.
30. Tuupanen S, Turunen M, Lehtonen R, Hallikas O, Vanharanta S, Kivioja T, Björklund M, Wei G, Yan J, Niittymäki I, et al: The common colorectal cancer predisposition SNP rs6983267 at chromosome 8q24 confers potential to enhanced Wnt signaling. Nat Genet 41: 885-890, 2009

31. Ling H, Spizzo R, Atlasi Y, Nicoloso M, Shimizu M, Redis RS, Nishida N, Gafà R, Song J, Guo Z, et al: CCAT2, a novel noncoding RNA mapping to $8 \mathrm{q} 24$, underlies metastatic progression and chromosomal instability in colon cancer. Genome Res 23: 1446-1461, 2013.

32. Sugimachi K, Niida A, Yamamoto K, Shimamura T, Imoto S, Iinuma $\mathrm{H}$, Shinden $\mathrm{Y}$, Eguchi $\mathrm{H}$, Sudo $\mathrm{T}$, Watanabe M, et al: Allelic imbalance at an 8q24 oncogenic SNP is involved in activating MYC in human colorectal cancer. Ann Surg Oncol 21 (Suppl 4): S515-S521, 2014.

33. Wright JB, Brown SJ and Cole MD: Upregulation of c-MYC in cis through a large chromatin loop linked to a cancer risk-associated single-nucleotide polymorphism in colorectal cancer cells. Mol Cell Biol 30: 1411-1420, 2010.

34. Chen J, Zhang JG, Li J, Pei YF and Deng HW: On combining reference data to improve imputation accuracy. PLoS One 8: e55600, 2013.

35. Paraf $\mathrm{F}$ and Jothy S: Colorectal cancer before the age of 40: A case-control study. Dis Colon Rectum 43: 1222-1226, 2000. 